Article

\title{
Hierarchical Porous MIL-101(Cr) Solid Acid-Catalyzed Production of Value-Added Acetals from Biomass-Derived Furfural
}

\author{
Shengqi Liu, Ye Meng, Hu Li *(i) and Song Yang *(D)
}

check for updates

Citation: Liu, S.; Meng, Y.; Li, H.; Yang, S. Hierarchical Porous MIL-101(Cr) Solid Acid-Catalyzed Production of Value-Added Acetals from Biomass-Derived Furfural. Polymers 2021, 13, 3498. https:// doi.org/10.3390/polym13203498

Academic Editor: Florian J. Stadler

Received: 6 August 2021

Accepted: 7 October 2021

Published: 12 October 2021

Publisher's Note: MDPI stays neutral with regard to jurisdictional claims in published maps and institutional affiliations.

Copyright: (c) 2021 by the authors. Licensee MDPI, Basel, Switzerland. This article is an open access article distributed under the terms and conditions of the Creative Commons Attribution (CC BY) license (https:/ / creativecommons.org/licenses/by/ $4.0 /)$.
State Key Laboratory Breeding Base of Green Pesticide and Agricultural Bioengineering, Key Laboratory of Green Pesticide \&Agricultural Bioengineering, Ministry of Education, State-Local Joint Laboratory for Comprehensive Utilization of Biomass, Center for Research and Development of Fine Chemicals, Guizhou University, Guiyang 550025, China; gs.liusq20@gzu.edu.cn (S.L.); m18334267276@163.com (Y.M.)

* Correspondence: hli13@gzu.edu.cn (H.L.); jhzx.msm@gmail.com (S.Y.)

Abstract: Considering economic and environmental impacts, catalytic biomass conversion to valuable compounds has attracted more and more attention. Of particular interest is furfural, a versatile biorefinery platform molecule used as a feedstock for the production of fuels and fine chemicals. In this study, the Cr-based metal-organic frameworks (MOFs) MIL-101 were modified by chlorosulfonic acid, and MIL-101 was changed into a hierarchical MOF structure with smaller particles and lower particle crystallinity by CTAB, which significantly improved the acidic sites of the MOFs. The original and modified MIL-101(Cr) catalysts were characterized by XRD, $\mathrm{N}_{2}$ adsorption-desorption, SEM, TEM, and FT-IR. The effects of different catalysts, reaction temperature, catalyst amount, and alcohol type on the reaction were studied. Under the action of the MOFs catalyst, a new mild route for the condensation of furfural with various alkyl alcohols to the biofuel molecules (acetals) was proposed. The conversion route includes the conversion of furfural up to $91 \%$ yield of acetal could be obtained within $1 \mathrm{~h}$ solvent-free and in room-temperature reaction conditions. The sulfonic acid-functionalized MIL-101(Cr) is easy to recover and reuse, and can still maintain good catalytic activity after ten runs.

Keywords: biomass conversion; MIL-101(Cr); furfural; green chemistry; heterogeneous catalysis

\section{Introduction}

At present, fossil carbon resources are the origin of more than $95 \%$ of the world's chemicals and materials. The use of renewable carbon resources to produce current and new generations of chemicals and materials has been highly valued [1]. The development of alternative technologies based on sustainable resources to offset the increase in fossil energy prices caused by depletion and global warming and minimize people's dependence on fossil fuel reserves is imminent [2,3]. Obtaining fuel alternatives from renewable biomass resources is a viable route. Lignocellulose is the second most abundant component in biomass. In recent years, some monomers in lignocellulosic biomass have been widely studied for their use in deriving more useful platform molecules, such as 5-hydroxymethylfurfural (HMF) and furfural (FUR) [4,5]. These chemical compounds are prepared by the dehydration of carbohydrates and are latently acceptable candidates for many fine chemicals currently derived from petroleum resources. FUR is a proverbial renewable platform molecule obtainable from biomass [6,7]. FUR and its derivatives have many commercial applications, including solvents, polymer monomers, and chemical raw materials for agrochemicals and medicines.

To enable the fuel properties of FUR through mixing with hydrocarbon fuels, it is usually necessary to reduce the polarity and volatility of its aldehyde group through functionalization procedures such as hydrogenation and alkylation [8]. Notably, catalytic acetalization of FUR and methanol can obtain furfural dimethyl acetal (FDMA) with 
high oxidation degrees as well as a high octane number, calorific value, and oxidation resistance $[9,10]$. This type of acetal has been used as additives for ethanol fuels to lower the auto-ignition temperature, and are considered biofuels or fuel precursors with huge potential demand [11]. FDMA also has industrial applications in the pharmaceutical, polymer, and perfume industries. At the same time, an acetal reaction is also an effective way to protect the carbonyl function of organic compounds [12-14]. Traditionally, acetal reactions are homogeneously catalyzed by a strong acid such as $\mathrm{H}_{2} \mathrm{SO}_{4}$ or $\mathrm{HCl}$. These mineral acids exhibit excellent catalytic effects in acetalization reactions, but result in many difficulties related to catalyst recovery, product separation, and equipment corrosion. In this sense, the development of an environmentally friendly solid acid catalyst with high activity is one of the major difficulties to be overcome [15]. Although solid acid catalysts such as phosphotungstic acid [16], $-\mathrm{SO}_{3} \mathrm{H}$-functionalized silica [17], lanthanum nitrate hexahydrate [18,19], graphene oxide [20], Fe-MIL-101 [21], $\mathrm{GaCl}_{3}$ immobilized on imidazolium-styrene copolymers [22], Zeolite [23], and phosphorylated polyacrylonitrile fibers [24] are not harmful to the environment, some supported solid acid catalysts require strenuous synthesis procedures and cause leaching or deactivation problems. It is therefore highly desirable to manufacture solid acid catalysts of high efficiency, e.g., by modifying the pore surface with strong acid sites [25]. Although many different kinds of functional groups can be introduced into metal-organic frameworks (MOFs) [26], it is hard to have strong acidity (e.g., sulfonic acid) after immobilizing onto the materials. If the part with Brønsted acid is used to construct the MOF skeleton, deprotonation will occur in the synthetic solution, which leads to the formation of MOF skeletons composed of conjugated Brønsted base sites $[27,28]$. A strong acid solution must be used as a synthesis solvent to avert the deprotonation of the acid group. Despite that most of the reported multiple MOFs or PCPs are decomposed in a strong acid solution, several robust MOFs are still stable enough. MIL-101(Cr) consisting of chromium oxide clusters and terephthalic acids are highly stable even in strong acid aqueous solutions because it is synthesized in a hydrofluoric acid medium [25]. In addition, MIL-101(Cr) material is characterized by high specific surface and easy exposure of acid sites [29].

In this work, a hierarchical porous solid acid catalyst MIL-101(Cr)- $\mathrm{SO}_{3} \mathrm{H}$, prepared by a one-pot modified hydrothermal method, was investigated for the catalytic acetalization of FUR. MIL-101(Cr)-SO ${ }_{3} \mathrm{H}$ bears good chemical and hydrothermal stability, and has a high surface area and excellent porosity properties, with unique 3D periodic mesocrystalline cages for the satisfactory decentralization and feasible accessibility of the $-\mathrm{SO}_{3} \mathrm{H}$ acid site to exhibit high performance in the catalytic acetalization of FUR under solvent-free conditions. Pristine and modified MIL-101(Cr) catalysts were characterized by XRD, SEM, TEM, FT-IR, and $\mathrm{N}_{2}$ adsorption, and the influence of the main reaction parameters was examined. Particular concern was paid to evaluate the reusability of MIL-101(Cr)- $\mathrm{SO}_{3} \mathrm{H}$ catalysts. In addition, the generality for synthesizing various furfural alkyl acetals by reaction with different alcohols was established.

\section{Materials and Methods}

\subsection{Materials}

Analytical grade terephthalic acid ( $99 \%), \mathrm{HF}$ ( $49 \%$ in water), cetyltrimethylammonium bromide (CTAB, $>99 \%)$, naphthalene $(99 \%$, internal standard), furfural $(99 \%)$, chromium nitrate nonahydrate $\left(\mathrm{Cr}\left(\mathrm{NO}_{3}\right)_{3} \cdot 9 \mathrm{H}_{2} \mathrm{O}, 99 \%\right)$, and $\mathrm{ClSO}_{3} \mathrm{H}$ were obtained from Beijing Chemical Reagent Company. Amberlyst-15 was purchased from Shanghai Aladdin Industrial Co., Ltd. (Lanzhou, China); Dichloromethane, methanol, ethanol, $n$-propanol, $n$-butanol, and isopropanol (AR) were purchased from Zhiyuan Chemical Reagent Company, Tianjin, China. Deionized water was prepared by Milli-Q Advantage A10 (Burlington, MA, USA) instrument. All reagents were purchased and used directly without any pretreatment. 


\subsection{Preparation of Catalyst}

\subsubsection{Preparation of Hierarchical Porous MIL-101(Cr)}

According to reported methods [30,31] with slight modification, hierarchical porous MIL-101(Cr) was prepared by hydrothermal treatment of $\mathrm{H}_{2}$ BDC (4 mmol, $\left.0.66 \mathrm{~g}\right), \mathrm{Cr}$ $\left(\mathrm{NO}_{3}\right)_{3} 9 \mathrm{H}_{2} \mathrm{O}(4 \mathrm{mmol}, 1.6 \mathrm{~g})$, the supramolecular templating agent CTAB $(1.2 \mathrm{mmol}$, $0.44 \mathrm{~g})$, and $\mathrm{HF}(0.13 \mathrm{~mL})$, in deionized water $(20 \mathrm{~mL})$. After stirring at room temperature for $30 \mathrm{~min}$, the obtained mixture was put into a $50 \mathrm{~mL}$ stainless steel autoclave lined with a Teflon, heated to $220^{\circ} \mathrm{C}$, and held for $8 \mathrm{~h}$. After the reaction, the autoclave was cooled to room temperature, and the reaction product was extracted three times with ethanol and deionized water to remove impurities and unreacted materials from the framework. Then, the purified MIL-101(Cr) (MC) was dried at $150{ }^{\circ} \mathrm{C}$ overnight, and stored in a desiccator after cooling to room temperature. Under the same conditions, the catalyst prepared without CTAB is defined as MA.

\subsubsection{Sulfonation of Hierarchical MIL-101(Cr)}

The MIL-101(Cr) $(0.33 \mathrm{~g})$ was activated at room temperature by stirring in $10 \mathrm{~mL}$ $\mathrm{CH}_{2} \mathrm{Cl}_{2}$ for $20 \mathrm{~min}$. To the resulting mixture, a $\mathrm{CH}_{2} \mathrm{Cl}_{2}$ solution containing $\mathrm{ClSO}_{3} \mathrm{H}(0.1 \mathrm{~mL}$ $\mathrm{ClSO}_{3} \mathrm{H}$ per $0.16 \mathrm{~g}$ solid) was slowly added dropwise under stirring conditions. After $4 \mathrm{~h}$, the obtained solid was washed and filtered with ethanol and $\mathrm{CH}_{2} \mathrm{Cl}_{2}$ until the lotion was neutral, followed by drying to obtain mesoporous MIL-101(Cr)-SO ${ }_{3} \mathrm{H}$ (MCS) [15,32]. MA was functionalized with sulfonic acid under the same conditions to obtain MAS.

\subsection{Characterization of the Catalyst}

Powder X-ray diffraction (XRD) analysis was obtained with a Bruker D8 Advanced X-ray diffractometer. The samples' chemical composition, morphology, and elemental diagrams were analyzed by field emission scanning electron microscopy (FE-SEM) (Zeiss SUPRA 55) at $20 \mathrm{kV}$. The outcome of the transmission electron microscopy (TEM) was furnished by a combined Philips Tecnai 20 and a JEOL JEM-2010 HR-TEM at 200 kV. First, we performed a degassing of the sample at $150^{\circ} \mathrm{C}$ for five $\mathrm{h}$, and then determined the nitrogen adsorption-desorption isotherm of the model at $-196^{\circ} \mathrm{C}$ through the Micromeritics ASAP 2020 system. The information obtained from the isotherm was used to determine the micropore volume, specific surface area, average micropore size, total pore volume, and pore size distribution. The extent of sulfonation and sulfonic acid amounts of MCS were detected by acid-base titration using a saturated $\mathrm{NaCl}$ solution to confirm the ion exchange. MCS $(0.5 \mathrm{~g})$ was suspended in $20 \mathrm{~g}$ of aqueous $\mathrm{NaCl}$ saturated solution. The mixed suspension was stirred at room temperature for more than $24 \mathrm{~h}$ to reach equilibrium, using $30 \mathrm{~mL}$ of deionized water for the next filtration and washing. Eventually, the achieved filtrate was titrated by a $0.1 \mathrm{M} \mathrm{NaOH}$ solution. The Fourier transform infrared spectrum (FT-IR) of the sample was recorded by a Nicolet 360 infrared spectrometer at $4000-500 \mathrm{~cm}^{-1}$, and $\mathrm{KBr}$ pellets were used to prepare the sample.

\subsection{General Procedure of Catalytic Reaction and Product Analysis}

All catalytic experiments were carried out at room temperature $\left(25^{\circ} \mathrm{C}\right)$ under vigorous stirring in a $15 \mathrm{~mL}$ Ace pressure tube. In a typical step, $96 \mathrm{mg}$ of furfural $(1 \mathrm{mmol}), 20 \mathrm{mg}$ of MCS, $16 \mathrm{mg}$ of naphthalene ( $0.125 \mathrm{mmol}$, internal standard), and $3 \mathrm{~mL}$ of methanol were loaded into a $15 \mathrm{~mL}$ reaction tube. The reaction solution was stirred violently at $25^{\circ} \mathrm{C}$ for $1 \mathrm{~h}$. The solid catalyst and supernatant were separated by centrifugation. The reaction mixture was analyzed afterward. The supernatant after centrifugation was filtered through a membrane to remove the remaining catalyst, and then the samples were analyzed qualitatively and quantitatively using gas chromatography-mass spectrometry (Agilent 6890-5973) and Agilent 7890 B gas chromatography. The conversion was obtained by comparing the GC peak areas of products and substrates with the calibration curves of standard samples. 
To study the recyclability of MCS. The catalyst was recovered at the end of the reaction, the identical experimental conditions as aforesaid were used. The reaction duration at every turn was $60 \mathrm{~min}$, and the reaction was essentially complete. The catalyst was washed three times separately with $30 \mathrm{~mL}$ of methanol, then dried in a vacuum oven at $80{ }^{\circ} \mathrm{C}$ for $12 \mathrm{~h}$ and directly reused in the next cycle.

\section{Results and Discussion}

\subsection{Characterization of Catalysts}

To reveal the crystal structure of the synthesized catalysts, the XRD technique was carried out. Figure 1 shows the XRD patterns of MA prepared without CTAB, MC synthesized in the presence of a $\mathrm{CTAB} / \mathrm{Cr}^{3+}$ molar ratio of 3 , and the materials MS and MCS after sulfonation. The XRD pattern of the prepared MA was in high coincidence with the simulated XRD pattern, and all the diffraction peaks of MAS, MC, and MCS were in accordance with the standard literature values [33], indicating that the MOF material was successfully prepared. Furthermore, it can be observed from the figure that the XRD pattern of MAS was similar to that of the original MA, showing that the crystal structure of MAS did not undergo any significant changes after the insertion of the $-\mathrm{SO}_{3} \mathrm{H}$ group into the MA backbone.

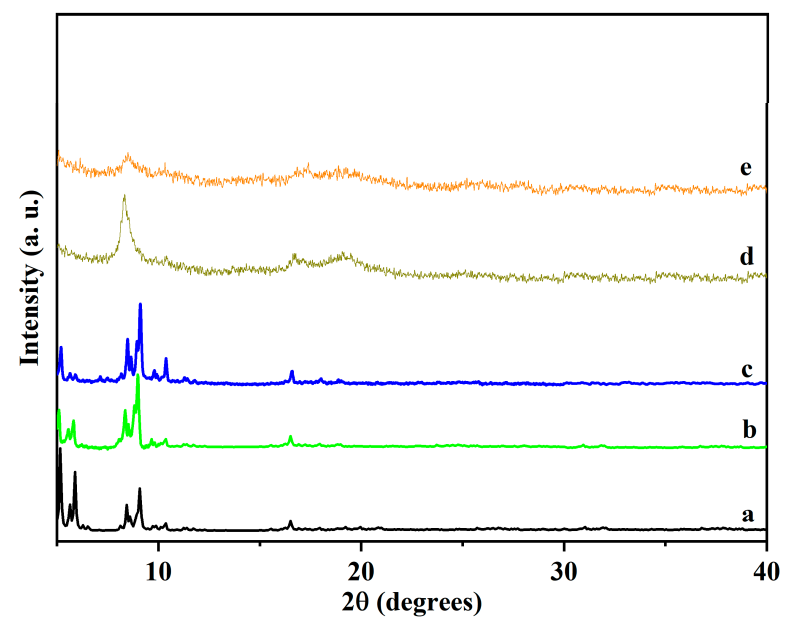

Figure 1. XRD patterns of (a) simulated MIL-101, (b) MA, (c) MAS, (d) MC, and (e) MCS.

The diffraction peaks become weaker and broader in Figure 1d,e, indicating smaller size particles and lower particle crystallinity in the sample. With the addition of CTAB, the crystallinity decreased and the structure became more irregular, which is consistent with previous reports [34].

The pristine and modified MIL-101(Cr) structures were characterized, and the SEM images are shown in Figure 2a-d. FE-SEM images of MA without CTAB addition demonstrate a typical octahedral morphology with nanocrystals of approximately $1 \mu \mathrm{m}$ in size (Figure 2a) [31], which correspond to pure MIL-101(Cr). By adding a certain amount of CTAB, samples with hierarchical porous structures different from the initial morphology were obtained. In addition, regular clusters of crystals about $600 \mathrm{~nm}$ in length and $100 \mathrm{~nm}$ in width were observed (Figure 2c), indicating that the mesoporous walls were formed by crystalline microporous frameworks. The observations show that CTAB has a very significant effect on MIL-101(Cr) crystal morphology, resulting in the outer surface of the nanocrystals becoming rough, which is consistent with the XRD observations. However, the sulfonic acid functionalization did not similarly affect the morphology (Figure 2b,d). Still, a significant etching of the sample can be seen, with a slight decrease in the size of the crystal particles [33]. 


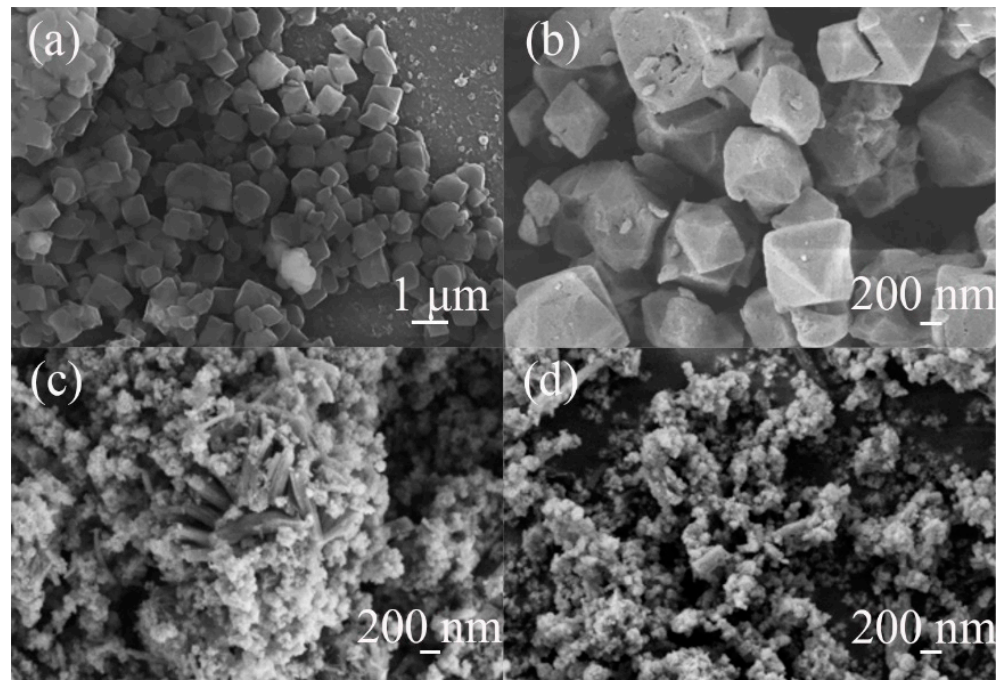

Figure 2. SEM images of: (a) MA, (b) MAS, (c) MC, and (d) MCS.

Figure 3 shows TEM images of the structure of hierarchical porous MOFs. The uniform bright and dark spots at $20 \mathrm{~nm}$ in Figure 3a, c show the presence of nanocrystals guided by cetyltrimethylammonium bromide. The appearance of bundled crystals indicates that the mesopore structure is basically consistent with the SEM images. The appearance of bunched crystals indicates that the mesopore wall is composed of uniform nanocrystals and random connections without long-range and regular order, which is consistent with the disordered wormhole structure reported in SEM images and in the literature [35]. Figure $3 b, d$ show that the catalyst appears in bundles and partially exists in the form of particles. It is further speculated that the action of CTAB causes most of the catalysts to reorganize in bundles and form an ordered hierarchical porous material, with the remaining part existing as microporous particles.

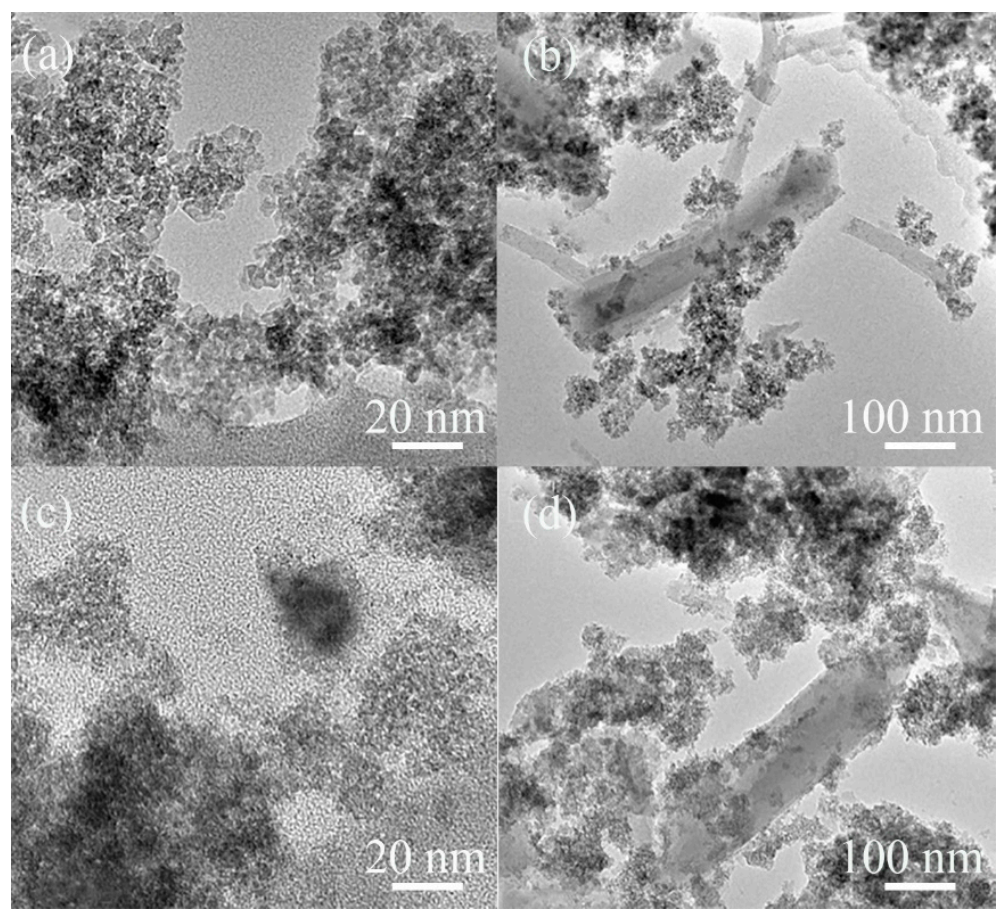

Figure 3. TEM images of $(\mathbf{a}, \mathbf{b}) \mathbf{M C}$ and (c,d) MCS in different scale plates. 
The diameter distribution of MCS was estimated using the software Nano measure 1.2 , based on 60 points in the TEM images, and the average particle size was found to be about $41.1 \mathrm{~nm}$ (Figure 4). To explore the role of CTAB in the preparation of catalysts, the particle size distribution of the MA and MC catalysts was estimated based on 60 points in the TEM images. The results show that CTAB can reduce the particle size of materials (Figure 5).
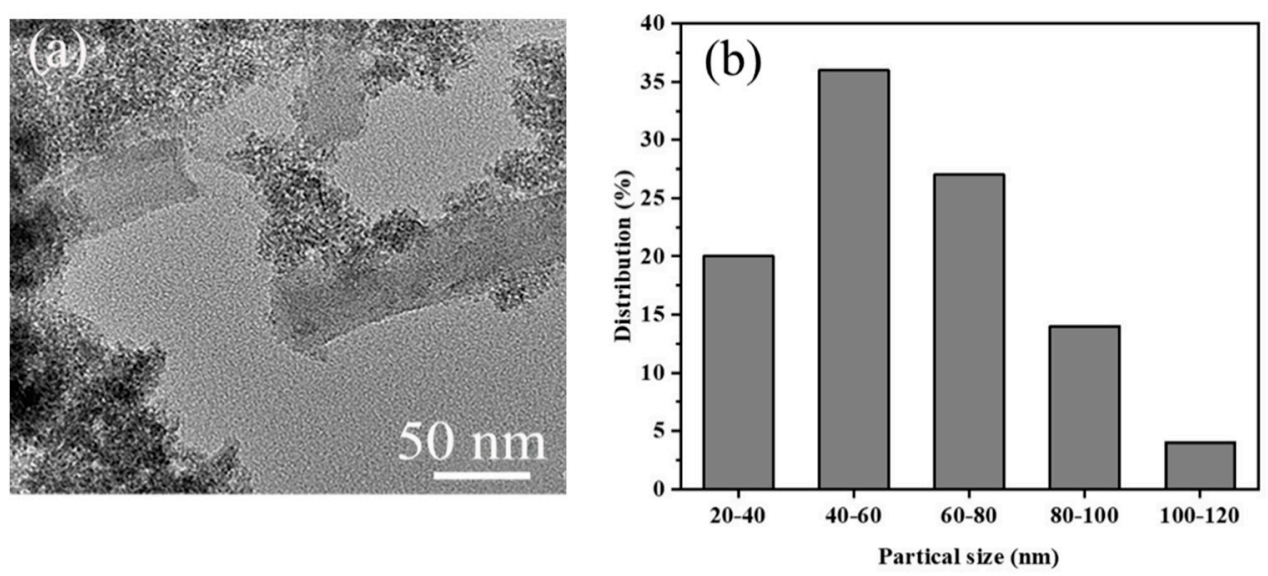

Figure 4. TEM image (a) and particle size distribution (b) of MCS.
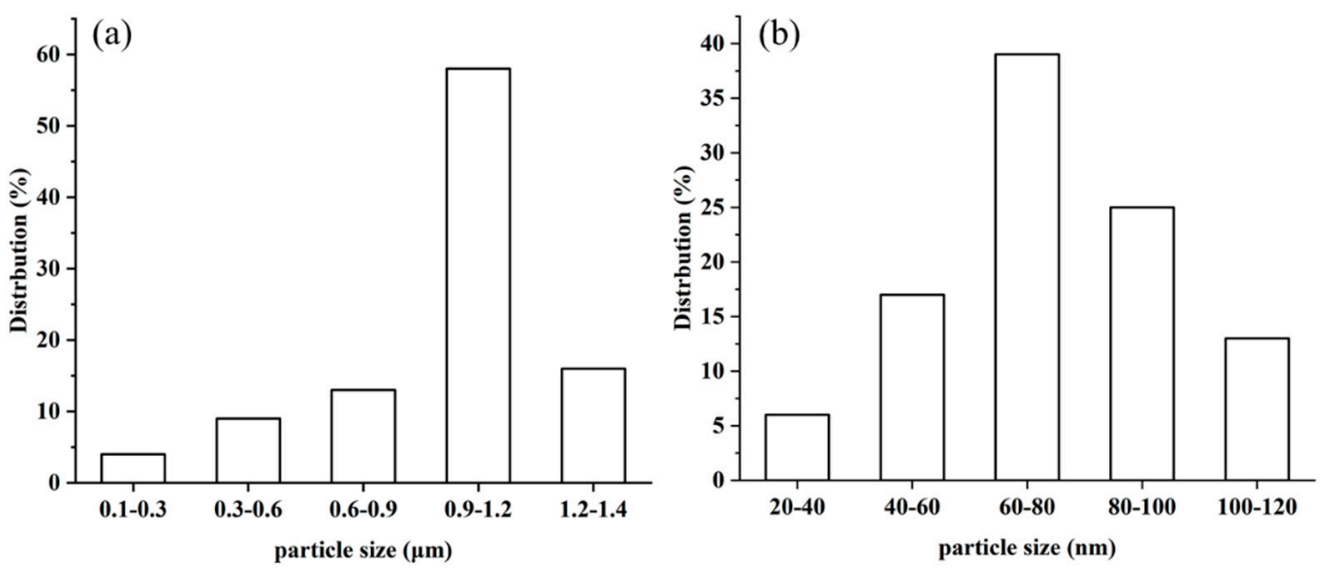

Figure 5. The particle size distribution of MA (a) and MC (b).

The FT-IR spectrum of MC indicated that the modification of MCS was successful, as shown in Figure 6a. All peaks of the original MC appear in the FT-IR spectrum of the modified MCS. The results also indicate that the modified MCS can maintain the basic structure. The characteristic peak at nearly $570 \mathrm{~cm}^{-1}$ is associated with $\mathrm{Cr}-\mathrm{O}$ stretching vibration. Most of the bands between $600 \sim 1600 \mathrm{~cm}^{-1}$ are attributed to $\mathrm{H}_{2} \mathrm{BDC}$ and its aromatic ring. Peaks at 750, 884, 1017, and $1160 \mathrm{~cm}^{-1}$ belong to the vibrations of $\mathrm{C}-\mathrm{H}$ groups in $-\mathrm{CH}_{3}$, and peaks at $1508 \mathrm{~cm}^{-1}$ belong to $\mathrm{C}=\mathrm{C}$ stretching vibrations. Peaks at 1173,1069 , and $670 \mathrm{~cm}^{-1}$ are attributed to an $\mathrm{O}=\mathrm{S}=\mathrm{O}$ symmetric stretching vibration, and the peak at $1702 \mathrm{~cm}^{-1}$ should be attributed to the $\mathrm{S}$ species. Therefore, it can be easily inferred that the $\mathrm{S}$ species was introduced in the form of $-\mathrm{SO}_{3}{ }^{-}$. In the absence of characteristic peaks of benzene rings replaced by sulfonic acid or sulfhydryl groups in the FT-IR spectra, all the $S$ species imported were substituted with the monocarboxylic acid regulators ligated to the $\mathrm{Cr}$ cluster. 

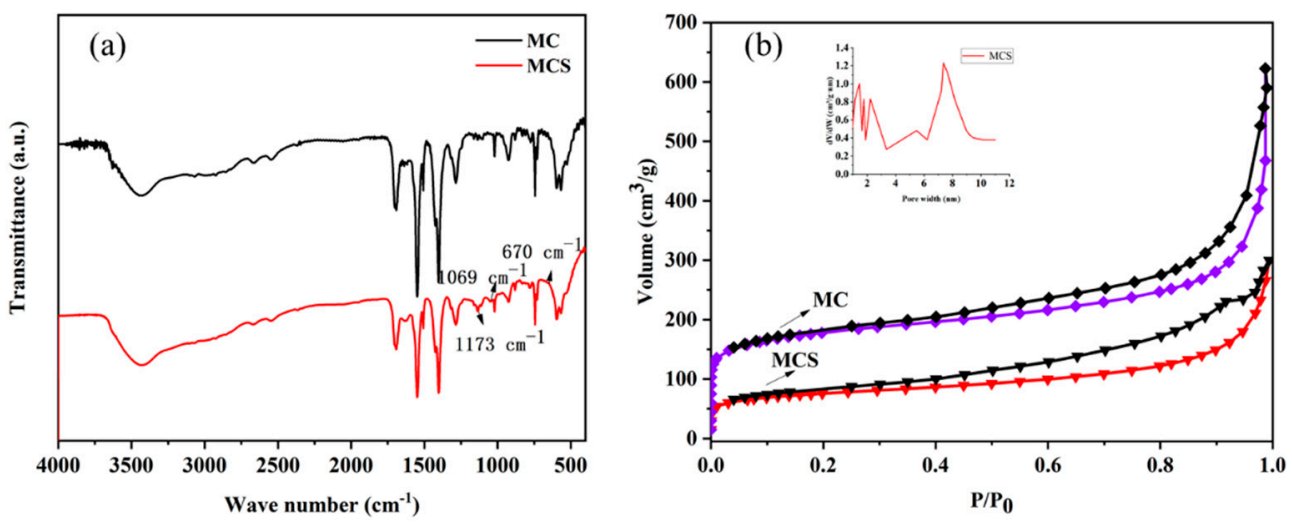

Figure 6. FT-IR spectra (a) and $\mathrm{N}_{2}$ adsorption-desorption isotherms (b) of pristine and modified MIL-101(Cr).

The porosity and structural parameters of the hierarchical porous MOFs materials were characterized using $\mathrm{N}_{2}$ adsorption-desorption isotherms at $-196{ }^{\circ} \mathrm{C}$ (Table 1 ). The hierarchical porous structures of $\mathrm{ClSO}_{3} \mathrm{H}$-functionalized and untreated $\mathrm{MOF}$ showed adjustable SBET, pore volume, pore size, and acid content after the addition of a certain amount of CTAB. As listed in Table 1, both $\mathrm{CTAB}$ and $\mathrm{ClSO}_{3} \mathrm{H}$ functionalization affected the pore size of the MOFs materials, and the pore size of these porous MOFs increased from 1.71 and $1.38 \mathrm{~nm}$ to 3.25 and $7.32 \mathrm{~nm}$ after CTAB treatment, respectively. This phenomenon was due to the accumulation of nanomaterials obtained [36,37]. After sulfonic acid functionalization, the acid content of MAS and MCS reached 0.36 and $0.65 \mathrm{mmol}$ $\left(\mathrm{H}^{+}\right) / \mathrm{g}$, respectively. Thus, the pore volume and Brunauer-Emmett-Taylor specific surface area (BET) of MOFs without functionalization of $\mathrm{ClSO}_{3} \mathrm{H}$ decreased rapidly, showing a more rapid downward trend than that of functionalized porous films. Transmission electron microscopy and pore size distribution (estimated from the Horvath-Kawazoe (HK) method) analyses showed that the catalyst structure consisted of good mesopores and micropores, which were identical with the XRD and SEM characterization.

Table 1. Physicochemical properties of various MIL-101 catalysts.

\begin{tabular}{ccccccc}
\hline Catalyst & Pore Size $(\mathbf{n m})$ & $\mathbf{S}_{\text {BET }}\left(\mathbf{m}^{\mathbf{2}} / \mathbf{g}\right)$ & $\mathbf{V}_{\mathbf{t}} \mathbf{( \mathbf { c m } ^ { \mathbf { 3 } } / \mathbf { g } )}$ & $\mathbf{V}_{\text {meso }}\left(\mathbf{c m}^{\mathbf{3}} \mathbf{g}\right)$ & $\mathbf{V}_{\text {meso }} / \mathbf{V}_{\text {micro }}$ & $\mathbf{A}_{\text {titration }}\left(\mathbf{m m o l}\left(\mathbf{H}^{+}\right) / \mathbf{g}\right)$ \\
\hline MA & 1.71 & 2603 & 1.30 & 0.39 & 0.42 & - \\
MAS & 1.38 & 1825 & 0.90 & 0.23 & 0.34 & 0.36 \\
MC & 3.25 & 638 & 0.51 & 0.28 & 1.22 & 0.03 \\
MCS & 7.32 & 197 & 0.30 & 0.18 & 1.50 & 0.65 \\
\hline
\end{tabular}

The $\mathrm{N}_{2}$ adsorption-desorption isotherms of MCS are shown in Figure $6 \mathrm{~b}$. In previous reports, the $\mathrm{P} / \mathrm{P}_{0}$ range of the $\mathrm{BET}$ assay was considered to be $0.005 \sim 0.05$. However, because MCS has microporous and mesoporous pore structures, the $\mathrm{P} / \mathrm{P}_{0}\left(\mathrm{P} / \mathrm{P}_{0}\right.$ relative pressure $)$ in the BET test ranged from 0.05-0.23. In general, the presence of hysteresis return lines at high relative pressures may be a sign of the dominance of structurally mediated pores. According to the IUPAC classification, the isotherms shown in Figure 6 can be classified as type IV isotherms. The pore size distribution of the catalyst (Figure 6) is identical with the hysteresis loop, which affirms the existence of mesopores in the material. All these experimental results underline the pivotal role of CTAB in the formation of micropores and good mesopores.

\subsection{Effect of Different Catalysts on the Acetalization of FUR with Methanol}

First, experiments on FUR acetalization catalyzed by different acidic catalysts were carried out in methanol. Of these catalysts, the catalytic and physical property results are shown in Table 2. It is worth noting that these solid acid catalysts were employed at the 
identical $\mathrm{H}^{+}$cation concentration. Control tests without any catalyst showed almost no acetal production, and no progression of the reaction was observed even with large excesses of methanol or extended reaction times (Table 2, entry 1). It shows that a catalyst is required to catalyze the acetal reaction. When MA was used as the catalyst, the existence of Lewis acid centered on chromium atoms improved its catalytic activity, but the monocarboxylic acid ligands coordinated on chromium atoms reduced the quantity of Lewis acid centers and further decreased the catalytic property (Table 2, entry 2). When MC was used, there is a certain but not significant increase in the yield (Table 2, entry 3), which is attributed to the increase in pore size and the probability of molecules entering the pore channel. However, when MCS was used as a catalyst, the modified monocarboxylic acid ligands were exchanged by $-\mathrm{SO}_{3} \mathrm{H}$ ligands, and more substantial acidic sites were introduced. As a result, the FDMA yield (91\%) was significantly improved (Table 2, entry 4 ), and the high catalytic activity of the catalyst was due to the highly decentralized acid sites and the hierarchical porous structure of MCS. The mesopore ensures free access of molecules to the active site.

Table 2. Conversion of FUR into FDMA over various catalysts ${ }^{\text {a }}$

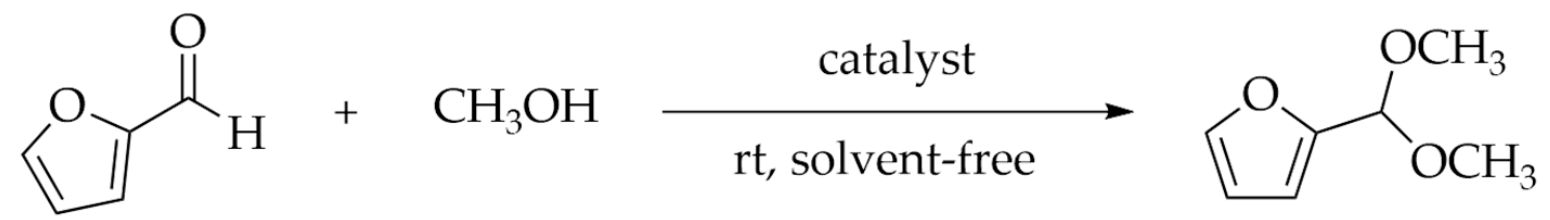

FUR

FDMA

\begin{tabular}{|c|c|c|c|c|c|c|}
\hline Entry & Catalyst & $\mathrm{S}_{\mathrm{BET}}\left[\mathrm{m}^{2} / \mathrm{g}\right]$ & Pore Volume $\left[\mathrm{cm}^{3} / \mathrm{g}\right]$ & $\mathbf{A}_{\text {titration }}\left[\mathrm{mmol}\left(\mathrm{H}^{+}\right) / \mathrm{g}\right]$ & Catalyst Amount (mg) & FDMA Yield (\%) \\
\hline 1 & No catalyst & - & - & - & - & 1 \\
\hline 2 & MA & 2594 & 1.30 & - & 20 & 9 \\
\hline 3 & MC & 638 & 0.51 & 0.03 & 20 & 25 \\
\hline 4 & MCS & 197 & 0.30 & 0.65 & 20 & 91 \\
\hline 5 & Amberlyst-15 & 50 & - & 4.70 & 5 & 63 \\
\hline 6 & H-USY(Si/Al = 6) & 37.6 & 0.08 & 1.40 & 5 & 71 \\
\hline $7^{\mathrm{b}}$ & $\mathrm{Cu}_{3}(\mathrm{BTC})_{2}$ & 1019 & - & - & 100 & 86 \\
\hline
\end{tabular}

a Reaction conditions: $1 \mathrm{mmol}$ furfural, catalyst with $3 \mathrm{~mol} \%$ acid content, $15 \mathrm{mg}(0.12 \mathrm{mmol})$ naphthalene (internal standard), $3 \mathrm{~mL}$ methanol, room temperature, and $1 \mathrm{~h}$ reaction time. ${ }^{\mathrm{b}}$ Reaction conditions: FUR $(1 \mathrm{mmol})$, methanol $(3 \mathrm{~mL}), \mathrm{Cu} 3(\mathrm{BTC}){ }_{2}(100 \mathrm{mg}), 24 \mathrm{~h}$, room temperature [34].

Interestingly, despite applying the same amount of acid catalyst, the catalytic effect was not so significant. Amberlyst-15, which has a relatively high number of acid sites, also gave only 63\% FDMA yield (Table 2, entry 5). On the other hand, H-USY gave a higher yield to FDMA than that offered by Amberlyst-15 (Table 2, entry 6). It can be seen that the formation of FDMA was not decided entirely by the number of acid centers present in the catalyst, but also the exposure of the acid sites. In addition, our catalyst was compared with the previous MOF material. According to the data of $\mathrm{Cu}_{3}(\mathrm{BTC})_{2}$ catalyzed furfural acetal reaction reported by Dhakshinamoorthy et al. [34], the catalytic effect of our developed catalyst MCS was better than that of $\mathrm{Cu}_{3}(\mathrm{BTC})_{2}$ (Table 2, entry 4 vs. 7). In all situations, FDMA was the unique product formed, and the gas chromatography detected the only product in the reaction. It is well known that the synthesis of FDMA needs to start from the formation of the corresponding hemiacetal. Still, no intermediates were detected in any reaction assay of this system. This indicates a faster and more complete build of acetals than hemiacetal formation, which agrees with other previously reported techniques.

\subsection{Effect of Catalyst Dosage on the Acetalization of FUR with Methanol}

Acetals are formed by acid-catalyzed reversible reactions, in which the catalyst is used to enhance the electrophilicity of FUR carbonyl carbon, thus allowing the reaction to proceed. The effect of catalyst dosage on the acetalization of FUR was investigated under typical experimental conditions (Figure 7a). By and large, the rise in the amount of catalyst 
means an increase in the number of acid-active sites usable for the catalytic procedure. Therefore, the conversion (i.e., reaction rate) is anticipated to rise if the reaction is under kinetic control. When a small amount of catalyst $(10 \mathrm{mg})$ was applied, the yield of the FDMA arrived $48 \%$ after $1 \mathrm{~h}$ of reaction, with some improvement in yield after a longer reaction time. This confirms that the catalyst maintains activity and requires only a longer reaction time to produce nearly the equivalent yield of FDMA, as an enormous amount of catalyst is present in a shorter reaction time. However, when higher loading catalysts were used, the yield of FDMA decreased to $86 \%$ and $83 \%$ when $40 \mathrm{mg}$ and $50 \mathrm{mg}$ MCS catalysts were used, respectively. The decrease in FDMA yield may be due to the excess acid that can protonate methanol and significantly reduce its nucleophilicity. Also, acid-catalyzed side reactions may occur, for instance, in the resinification of FUR.

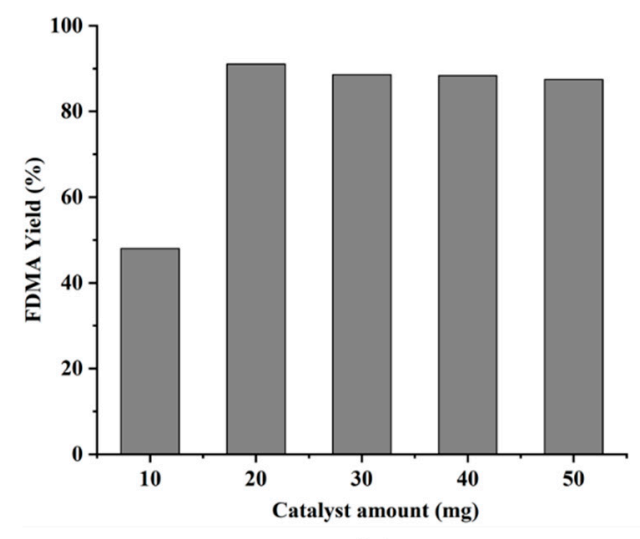

(a)

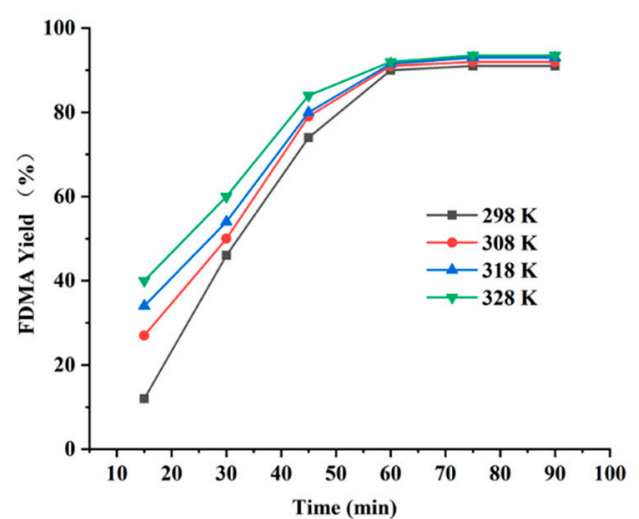

(b)

Figure 7. (a) The influence of MCS catalyst amount on the yield of FDMA synthesized from FUR acetalization. (b) The influence of temperature on the yield of the FDMA. Reaction conditions: $96 \mathrm{mg}$ FUR (1 mmol), $3 \mathrm{~mL}$ methanol (74 mmol), room temperature for $1 \mathrm{~h}$.

\subsection{Effect of Temperature on the Acetalization of FUR with Methanol}

The catalytic performance of MCS for methanol FUR acetalization at different temperatures was investigated. As shown in Figure $7 \mathrm{~b}$, the main observation is that although the initial rate of the reaction is affected by the rapid increase of temperature, the final yield is very close. When the reaction is carried out at a higher temperature, the number of effective collisions increases. Therefore, the products (e.g., FUR, diethyl acetal, and water) were formed rapidly. However, the reaction almost reached equilibrium after $60 \mathrm{~min}$. The main reason may be that the reaction equilibrium may be transferred to the reactant in the presence of more water. This is also the main reason why the temperature had no noticeable effect on the reaction when the yield reached a particular value.

\subsection{Substrate Test}

In order to evaluate the importance of appropriate pore size in MOF structures in acetalization, as a comparative experiment, different aldehydes were catalyzed by MCS in methanol. The obtained results are shown in Table 3. It is reported that aliphatic aldehydes have low reactivity to the formation of corresponding dimethylacetals [38]. However, aliphatic aldehydes also showed high reactivity in the presence of the MCS catalyst (Table 3, entries 1-3). In addition, structurally rigid aromatic aldehydes can also be converted to corresponding dimethyl acetals with excellent conversion (Table 2, entry 6). 
Table 3. Acetalization of various aldehydes was catalyzed by MCS with methanol ${ }^{\mathrm{a}}$.

Entry

a Reaction conditions: $1 \mathrm{mmol}$ aldehyde, catalyst with $3 \mathrm{~mol} \%$ acid content, $15 \mathrm{mg}(0.12 \mathrm{mmol})$ naphthalene (internal standard), $3 \mathrm{~mL}$ methanol, room temperature, and $1 \mathrm{~h}$ reaction time.

The length of the alcohol carbon chain and the spatial site resistance around the hydroxyl group are the primary characteristics that affect the activity of alcohol reactions. Therefore, the catalytic performance of MCS catalysts in the acetalization reactions of FUR with different alcohols was evaluated at room temperature. The results are summarized in Figure 8a.

In the presence of the MCS catalyst, the changing trend of alcohol activity was methanol $>$ ethanol $>$ propanol $>$ butanol $>$ isopropanol. The activity of furfural acetalization can be attributed to the steric hindrance of isopropanol on the hydroxyl group as the reason for the lowest reaction activity on one hand, while on the other hand, the decrease of reactivity with the increase of carbon chain length can be attributed to the $p K a$ effect of alcohol. The $p K a$ effect of alcohol decreases with the increase of carbon chain length, which reduces the reactivity of alcohol in FUR acetalization. Although two aspects (i.e., the spatial resistance on the hydroxyl group and the size of the carbon chain) may affect the alcohol reactivity in FUR acetalization, it is evident from the results that the spatial resistance on the hydroxyl group has a more significant effect on acetal formation than the length of the alcohol carbon. Regardless of the alcohol substrate employed, all reactions achieved complete conversion in a short reaction time, with the exclusive product being detected. 


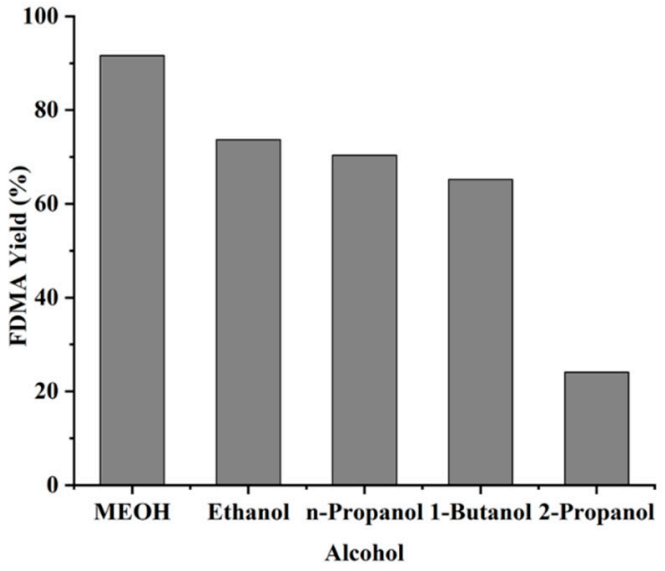

(a)

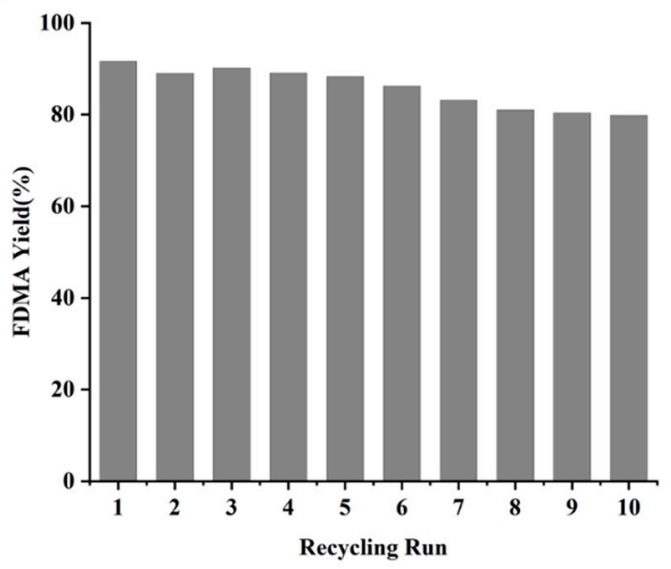

(b)

Figure 8. (a) Effect of alcohol on the FUR acetalization catalyzed by MCS. (b) Reuse of MCS catalyst in FUR acetalization.

\subsection{Catalyst Recycling Study}

Reusability is a crucial characteristic of catalysts, so it is necessary to investigate the recyclability of MCS. Interestingly, the recovered MCS exhibited relatively stable catalytic activity after the initial run, with a slight decrease in activity after ten runs (Figure $8 \mathrm{~b}$ ), indicating that the $\mathrm{ClSO}_{3} \mathrm{H}$-modified MIL-101(Cr) catalyst has high stability. This demonstrates that MOF is an excellent solid acid catalyst with increased stability in catalytic acetalization. The XRD patterns and FT-IR spectra (Figure 9) of the fresh MCS and reused MCS catalysts showed that the integrity of $-\mathrm{SO}_{3} \mathrm{H}$ ligands and crystals were well retained after ten cycles.
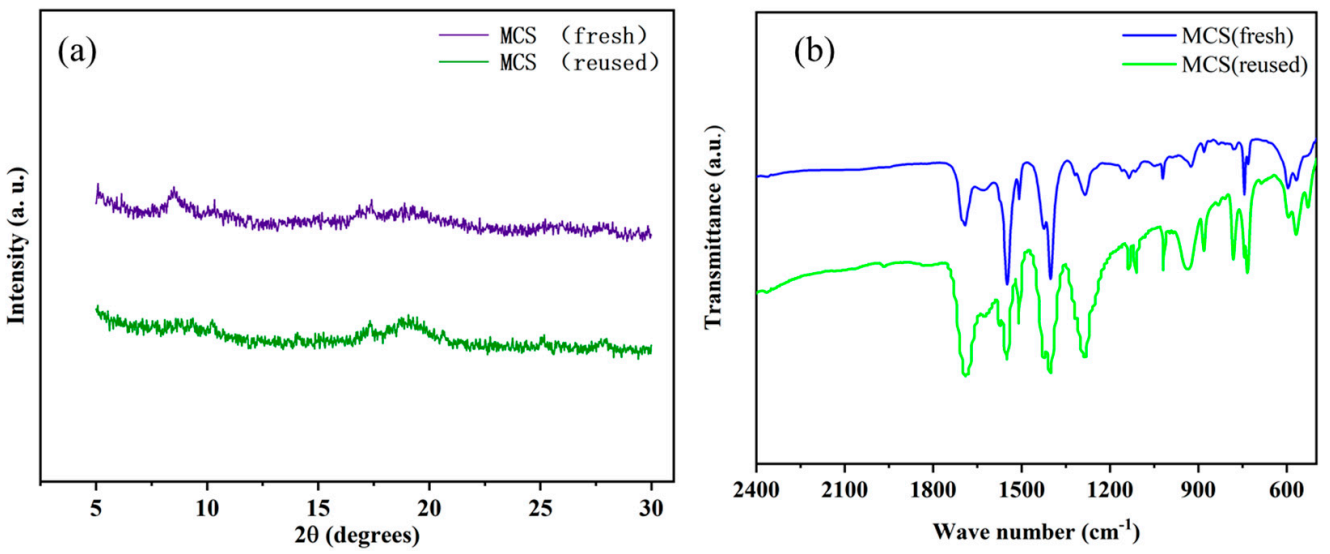

Figure 9. XRD patterns (a) and FT-IR spectra (b) of the fresh and reused MCS catalysts.

\section{Conclusions}

In summary, the original catalyst and the $\mathrm{ClSO}_{3} \mathrm{H}$ modified MIL-101(Cr) catalyst were characterized by TEM, XRD, SEM, $\mathrm{N}_{2}$ adsorption-desorption, and infrared spectroscopy. The results showed that the hierarchical porous catalyst MCS has chemical and hydrothermal stability, high specific surface area, good porosity, and a unique three-dimensional periodic cage with good dispersion and feasible accessibility of the $-\mathrm{SO}_{3} \mathrm{H}$ acid sites. The catalytic activity of MCS as a reusable solid acid catalyst for the acetalization of FUR with methanol was also studied. In the presence of MCS, FUR could react with methanol to form the expected dimethanol acetal with up to $91 \%$ yield in $1 \mathrm{~h}$. The high catalytic activity of MCS may be due to the suitable Brønsted acid sites and hierarchical porous structure, which ensures that the reaction substrate can enter the MOFs freely. The MCS catalyst is a highly recyclable solid acid catalyst in acetalization, with potential for industrial applica- 
tions because its high catalytic activity and structural integrity can be maintained after ten times of continuous use.

Author Contributions: Methodology, writing—original draft, investigation, S.L.; conceptualization, writing-review and editing, supervision, project administration, H.L.; writing-review and editing, Y.M.; supervision, funding acquisition, S.Y. All authors have read and agreed to the published version of the manuscript.

Funding: This research was financially supported by the National Natural Science Foundation of China (21908033, 21576059, 21666008), the Fok Ying-Tong Education Foundation (161030), the Program of Introducing Talents of Discipline to Universities of China (111 Program, D20023), and the Guizhou Frontiers Science Center for Asymmetric Synthesis and Medicinal Molecules ([2020]004).

Institutional Review Board Statement: Not applicable.

Informed Consent Statement: Not applicable.

Data Availability Statement: Raw data of this work is available upon request from the corresponding author.

Conflicts of Interest: The authors declare no conflict of interest.

\section{References}

1. Bozell, J.J.; Petersen, G.R. Technology development for the production of biobased products from biorefinery carbohydrates-The US Department of Energy's “Top 10" revisited. Green Chem. 2010, 12, 539-554. [CrossRef]

2. Mika, L.T.; Csefalvay, E.; Nemeth, A. Catalytic Conversion of Carbohydrates to Initial Platform Chemicals: Chemistry and Sustainability. Chem. Rev. 2018, 118, 505-613. [CrossRef]

3. He, J.; Li, H.; Saravanamurugan, S.; Yang, S. Catalytic Upgrading of Biomass-Derived Sugars with Acidic Nanoporous Materials: Structural Role in Carbon-Chain Length Variation. ChemSusChem 2019, 12, 347-378. [CrossRef]

4. Cai, C.M.; Zhang, T.; Kumar, R.; Wyman, C.E. Integrated furfural production as a renewable fuel and chemical platform from lignocellulosic biomass. J. Chem. Technol. Biotechnol. 2014, 89, 2-10. [CrossRef]

5. Weingarten, R.; Cho, J.; Conner, J.W.C.; Huber, G.W. Kinetics of furfural production by dehydration of xylose in a biphasic reactor with microwave heating. Green Chem. 2010, 12, 1423-1429. [CrossRef]

6. Lange, J.P.; van der Heide, E.; van Buijtenen, J.; Price, R. Furfural a promising platform for lignocellulosic biofuels. ChemSusChem 2012, 5, 150-166. [CrossRef]

7. Li, H.; Fang, Z.; Smith, R.L.; Yang, S. Efficient valorization of biomass to biofuels with bifunctional solid catalytic materials. Prog. Energy Combust. 2016, 55, 98-194. [CrossRef]

8. Stepan, E.; Enascuta, C.E.; Oprescu, E.E.; Radu, E.; Vasilievici, G.; Radu, A.; Stoica, R.; Velea, S.; Nicolescu, A.; Lavric, V. A versatile method for obtaining new oxygenated fuel components from biomass. Ind. Crop. Prod. 2018, 113, 288-297. [CrossRef]

9. Alipour, S.; Omidvarborna, H.; Kim, D.S. A review on synthesis of alkoxymethyl furfural, a biofuel candidate. Renew. Sust. Energy Rev. 2017, 71, 908-926. [CrossRef]

10. Tarabanko, V.E.; Chernyak, M.Y.; Simakova, I.L.; Kaigorodov, K.L.; Bezborodov, Y.N.; Orlovskaya, N.F. Antiknock properties of furfural derivatives. Russ. J. Appl. Chem. 2016, 88, 1778-1782. [CrossRef]

11. Manzetti, S.; Andersen, O. A review of emission products from bioethanol and its blends with gasoline. Background for new guidelines for emission control. Fuel 2015, 140, 293-301. [CrossRef]

12. Senthur Prabu, S.; Asokan, M.A.; Prathiba, S.; Ahmed, S.; Puthean, G. Effect of additives on performance, combustion and emission behavior of preheated palm oil/diesel blends in DI diesel engine. Renew. Energy 2018, 122, 196-205. [CrossRef]

13. Kirchhecker, S.; Dell'Acqua, A.; Angenvoort, A.; Spannenberg, A.; Ito, K.; Tin, S.; Taden, A.; de Vries, J.G. HMF-glycerol acetals as additives for the debonding of polyurethane adhesives. Green Chem. 2021, 23, 957-965. [CrossRef]

14. Appaturi, J.N.; Jothi Ramalingam, R.; Al-Lohedan, H.A.; Khoerunnisa, F.; Ling, T.C.; Ng, E.P. Selective synthesis of dioxolane biofuel additive via acetalization of glycerol and furfural enhanced by MCM-41-alanine bifunctional catalyst. Fuel 2021, 288, 119573-119584. [CrossRef]

15. Dhakshinamoorthy, A.; Asiri, A.M.; Garcia, H. Formation of C-C and C-Heteroatom Bonds by C-H Activation by Metal Organic Frameworks as Catalysts or Supports. ACS Catal. 2018, 9, 1081-1102. [CrossRef]

16. Teixeira, M.G.; Natalino, R.; da Silva, M.J. A kinetic study of heteropolyacid-catalyzed furfural acetalization with methanol at room temperature via ultraviolet spectroscopy. Catal. Today 2020, 344, 143-149. [CrossRef]

17. Shimizu, K.I.; Hayashi, E.; Hatamachi, T.; Kodama, T.; Kitayama, Y. $\mathrm{SO}_{3} \mathrm{H}$-functionalized silica for acetalization of carbonyl compounds with methanol and tetrahydropyranylation of alcohols. Tetrahedron Lett. 2004, 45, 5135-5138. [CrossRef]

18. Wu, S.; Dai, W.; Yin, S.; Li, W.; Au, C.T. Bismuth subnitrate as an efficient heterogeneous catalyst for acetalization and ketalization of carbonyl compounds with diols. Catal. Lett. 2008, 124, 127-132. [CrossRef] 
19. Srinivasulu, M.; Suryakiran, N.; Rajesh, K.; Malla Reddy, S.; Venkateswarlu, Y. Mild and efficient chemoselective synthesis of acetals and geminal diacetates (acylals) from aldehydes using lanthanum (III) nitrate hexahydrate. Synth. Commun. 2008, 38, 1753-1759. [CrossRef]

20. Dhakshinamoorthy, A.; Alvaro, M.; Puche, M.; Fornes, V.; Garcia, H. Graphene oxide as catalyst for the acetalization of aldehydes at room temperature. ChemCatChem 2012, 4, 2026-2030. [CrossRef]

21. Yang, M.; Tang, J.; Ma, Q.; Zheng, N.; Tan, L. High activity Fe-MIL-101 solid acid catalyst for acetalization of aldehydes with methanol and enamination of $\beta$-dicarbonyl compounds. J. Porous Mat. 2015, 22, 1345-1350. [CrossRef]

22. Bao, Q.; Qiao, K.; Tomida, D.; Yokoyama, C. Acetalization of carbonyl compounds catalyzed by $\mathrm{GaCl}_{3}$ immobilized on imidazolium-styrene copolymers. Catal. Commun. 2009, 10, 1625-1628. [CrossRef]

23. Rubio-Caballero, J.M.; Saravanamurugan, S.; Maireles-Torres, P.; Riisager, A. Acetalization of furfural with zeolites under benign reaction conditions. Catal. Today 2014, 234, 233-236. [CrossRef]

24. Xu, G.; Cao, J.; Zhao, Y.; Zheng, L.; Tao, M.; Zhang, W. Phosphorylated polyacrylonitrile fibers as an efficient and greener acetalization catalyst. Chem. Asian. J. 2017, 12, 2565-2575. [CrossRef] [PubMed]

25. Akiyama, G.; Matsuda, R.; Sato, H.; Takata, M.; Kitagawa, S. Cellulose hydrolysis by a new porous coordination polymer decorated with sulfonic acid functional groups. Adv. Mater. 2011, 23, 3294-3297. [CrossRef]

26. Fang, R.; Dhakshinamoorthy, A.; Li, Y.; Garcia, H. Metal organic frameworks for biomass conversion. Chem. Soc. Rev. 2020, 49, 3638-3687. [CrossRef]

27. Hong, D.Y.; Hwang, Y.K.; Serre, C.; Férey, G.; Chang, J.S. Porous chromium terephthalate MIL-101 with coordinatively unsaturated sites: Surface functionalization, encapsulation, sorption and catalysis. Adv. Funct. Mater. 2009, 19, 1537-1552. [CrossRef]

28. Isaeva, V.I.; Nefedov, O.M.; Kustov, L.M. Metal-Organic Frameworks-Based Catalysts for Biomass Processing. Catalysts 2018, 8, 368. [CrossRef]

29. Liu, X.; Liu, Z.; Wang, R. Functionalized Metal-Organic Framework Catalysts for Sustainable Biomass Valorization. Adv. Polym. Tech. 2020, 2020, 1201923. [CrossRef]

30. Qiu, L.G.; Xu, T.; Li, Z.Q.; Wang, W.; Wu, Y.; Jiang, X.; Tian, X.Y.; Zhang, L.D. Hierarchically micro- and mesoporous metal-organic frameworks with tunable porosity. Angew. Chem. Int. Ed. Engl. 2008, 47, 9487-9491. [CrossRef]

31. Hasan, Z.; Jun, J.W.; Jhung, S.H. Sulfonic acid-functionalized MIL-101(Cr): An efficient catalyst for esterification of oleic acid and vapor-phase dehydration of butanol. Chem. Eng. J. 2015, 278, 265-271. [CrossRef]

32. Pourreza, A.; Askari, S.; Rashidi, A.; Seif, A.; Kooti, M. Highly efficient $\mathrm{SO}_{3}$ Ag-functionalized MIL-101(Cr) for adsorptive desulfurization of the gas stream: Experimental and DFT study. Chem. Eng. J. 2019, 363, 73-83. [CrossRef]

33. Huang, X.X.; Qiu, L.G.; Zhang, W.; Yuan, Y.P.; Jiang, X.; Xie, A.J.; Shen, Y.H.; Zhu, J.F. Hierarchically mesostructured MIL-101 metal-organic frameworks: Supramolecular template-directed synthesis and accelerated adsorption kinetics for dye removal. CrystEngComm 2012, 14, 1613-1617. [CrossRef]

34. Dhakshinamoorthy, A.; Alvaro, M.; Garcia, H. Metal Organic Frameworks as Solid Acid Catalysts for Acetalization of Aldehydes with Methanol. Adv. Synth. Catal. 2010, 352, 3022-3030. [CrossRef]

35. Pham, M.-H.; Vuong, G.-T.; Fontaine, F.-G.; Do, T.-O. A Route to Bimodal Micro-Mesoporous Metal-Organic Frameworks Nanocrystals. Cryst. Growth Des. 2011, 12, 1008-1013. [CrossRef]

36. Seoane, B.; Dikhtiarenko, A.; Mayoral, A.; Tellez, C.; Coronas, J.; Kapteijn, F.; Gascon, J. Metal organic framework synthesis in the presence of surfactants: Towards hierarchical MOFs? CrystEngComm 2015, 17, 1693-1700. [CrossRef] [PubMed]

37. Li, J.X.; Chang, G.G.; Tian, G.; Pu, C.; Huang, K.X.; Ke, S.C.; Janiak, C.; Yang, X.Y. Near-Linear Controllable Synthesis of Mesoporosity in Hierarchical UiO-66 by Template-Free Nucleation-Competition. Adv. Funct. Mater. 2021, 31, $2102868-2102875$. [CrossRef]

38. Tateiwa, J.; Horiuchi, H.; Uemura, S. Ce ${ }^{3+}$-Exchanged Montmorillonite (Ce ${ }^{3+}$-Mont) as a Useful Substrate-Selective Acetalization Catalyst. J. Org. Chem. 1995, 60, 4039-4043. [CrossRef] 